\title{
Does Computerized Cognitive Training help to improve cognitive performance in the elderly adults? The study report.
}

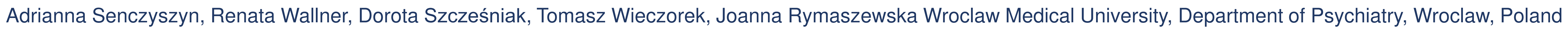

\section{OBJECTIVES}

To evaluate the impact of Computerized Cognitive Training on the cognitive performance of older adults with and without cognitive impairment.

\section{METHODS}

Timeframe:

9 weeks x 90' minutes

\begin{tabular}{c|} 
Training part \\
\hline PSYCHOEDUCATION \\
about cognitive functions \\
and ways of stimulation
\end{tabular}

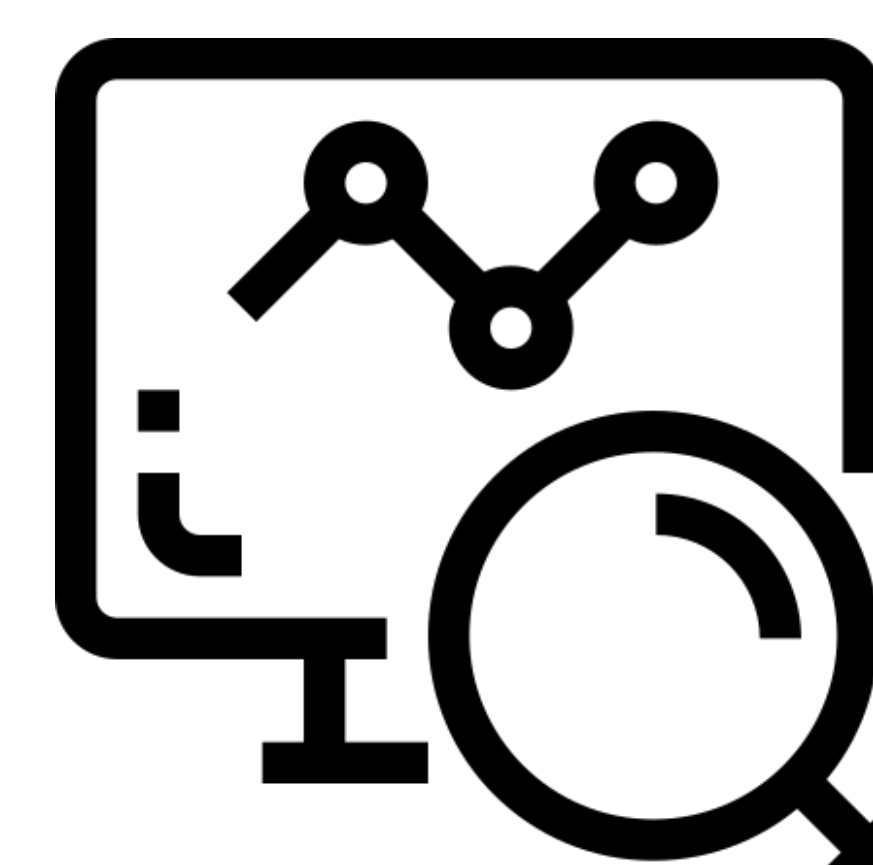

Workshop part

EXERCISE of the

efficiency of individual

cognitive domains:

individual tasks

computer tasks

group discussions

homework assignments
STUDY SAMPLE

Participants: 51 seniors

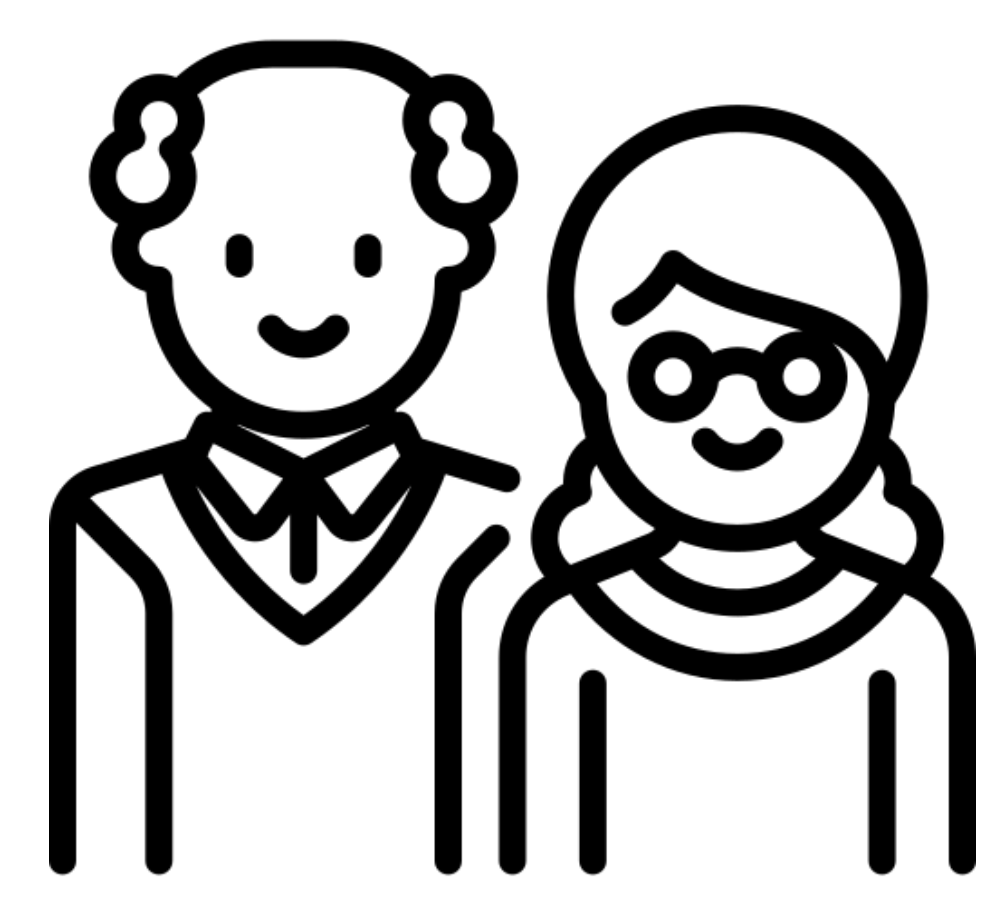

TWO HOMOGENEOUS GROUPS:

\begin{tabular}{ll|ll} 
Experimental group & \multicolumn{2}{|c}{ Control group } \\
\hline Seniors: & $\mathbf{3 2 ( + 6 5 )}$ & Seniors: & $\mathbf{2 0}(+65)$ \\
Female: & $\mathbf{2 2}$ & Female: & $\mathbf{1 5}$ \\
Male: & $\mathbf{1 0}$ & Male: & $\mathbf{5}$ \\
Mean age: & $\mathbf{7 1 . 1 8}$ & Mean age: & $\mathbf{7 0}$ \\
Mean MoCA: & $\mathbf{2 4 . 3 2}$ & Mean MoCA: & $\mathbf{2 3 . 5}$ \\
Mean GDS: & $\mathbf{8 . 5}$ & Mean GDS: & $\mathbf{7 . 8}$
\end{tabular}

The assesment of COGNITIVE PERFORMANCE before and after the CCT with RBANS battery (Randolph,1998)

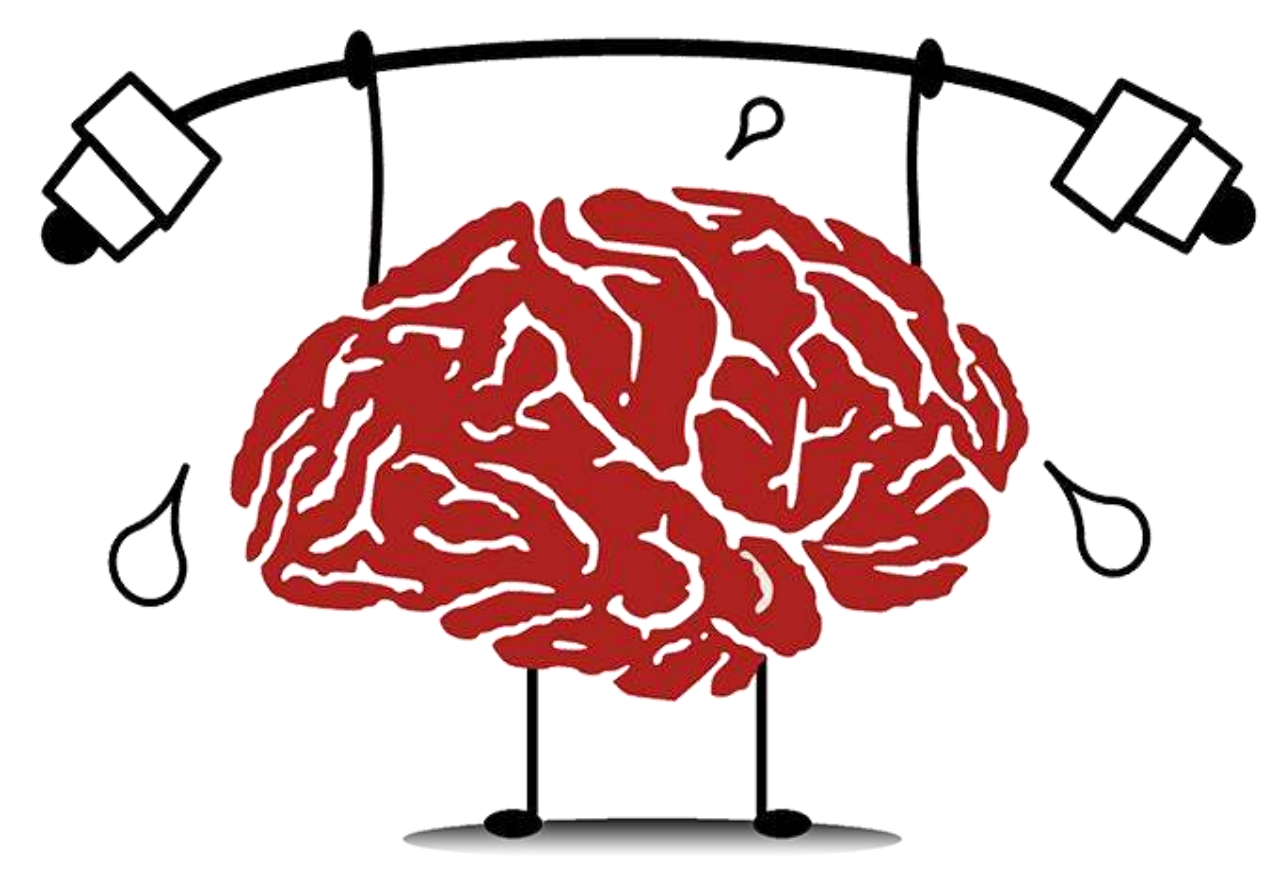

The ADAPTIVE NATURE OF TASKS - their level adapts to the progress made by the participants.

Professional tRaINER experienced in working with seniors.

\section{RESULTS AND CONCLUSIONS}

NO CLINICALLY VALID IMPROVEMENT IN THE DEPRESSION ASSESSMENT (EG: T1 GDS=8.5, T2 GDS=7.4, $\mathrm{p}=0.23$; $\mathrm{CG}$ T1 GDS=7.8, T2 GDS=8.5, $\mathrm{p}=0.6$ )

EG IN T2 IMPROVED IN 8 OUT OF 12 RBANS SUBTESTS (8 subtests evaluating the efficiency of immediate and delayed memory, attention, semantic fluency) $(p<0.05)$, see the chart presented below:

40,0

35,0

$$
30,0
$$$$
25,0
$$$$
20,0
$$$$
15,0
$$$$
10,0
$$$$
5,0
$$$$
0,0
$$
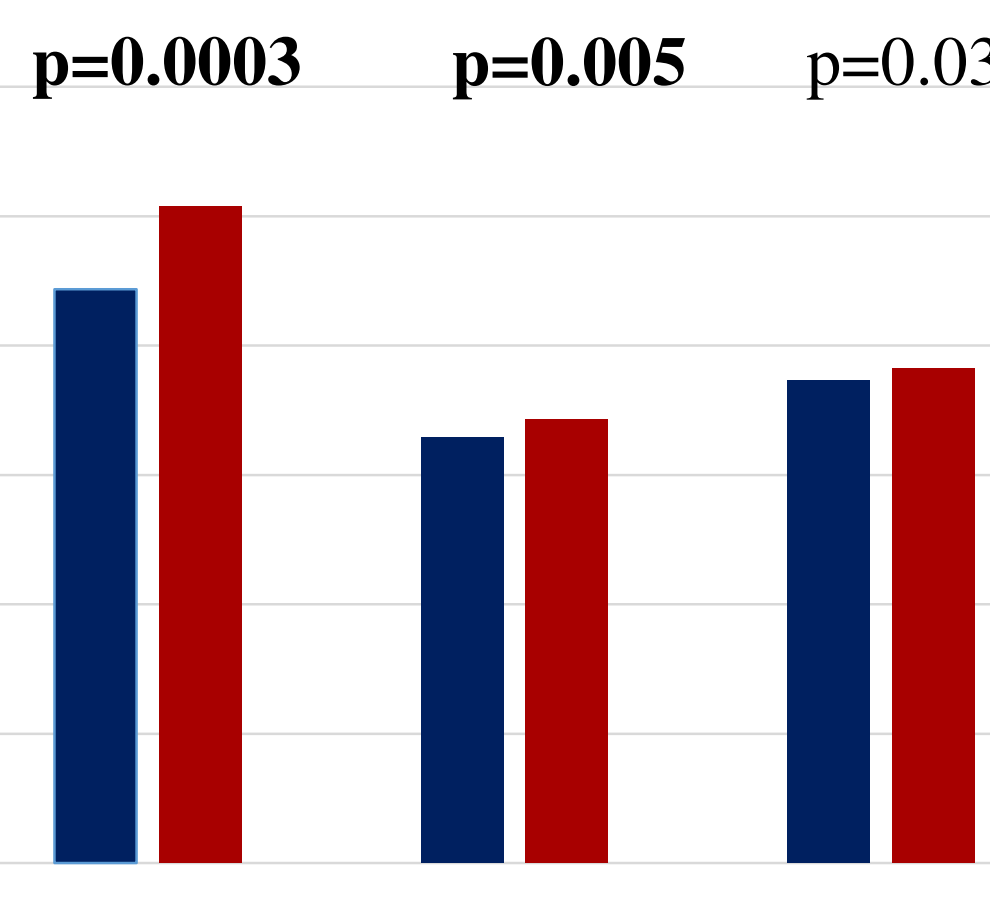

$\mathrm{p}=\mathbf{0}$

$\mathrm{p}=0.07$

$\mathrm{p}=\mathbf{0 . 0 0 6}$

$\mathrm{p}=0.65$

MEMORY
Story memory Figure copy Line orientation Picture naming

MEMORY VISUOSPATIAL VISUOSPATIAL LANGUAGE Semantic fluency $\mathrm{p}=0.09$
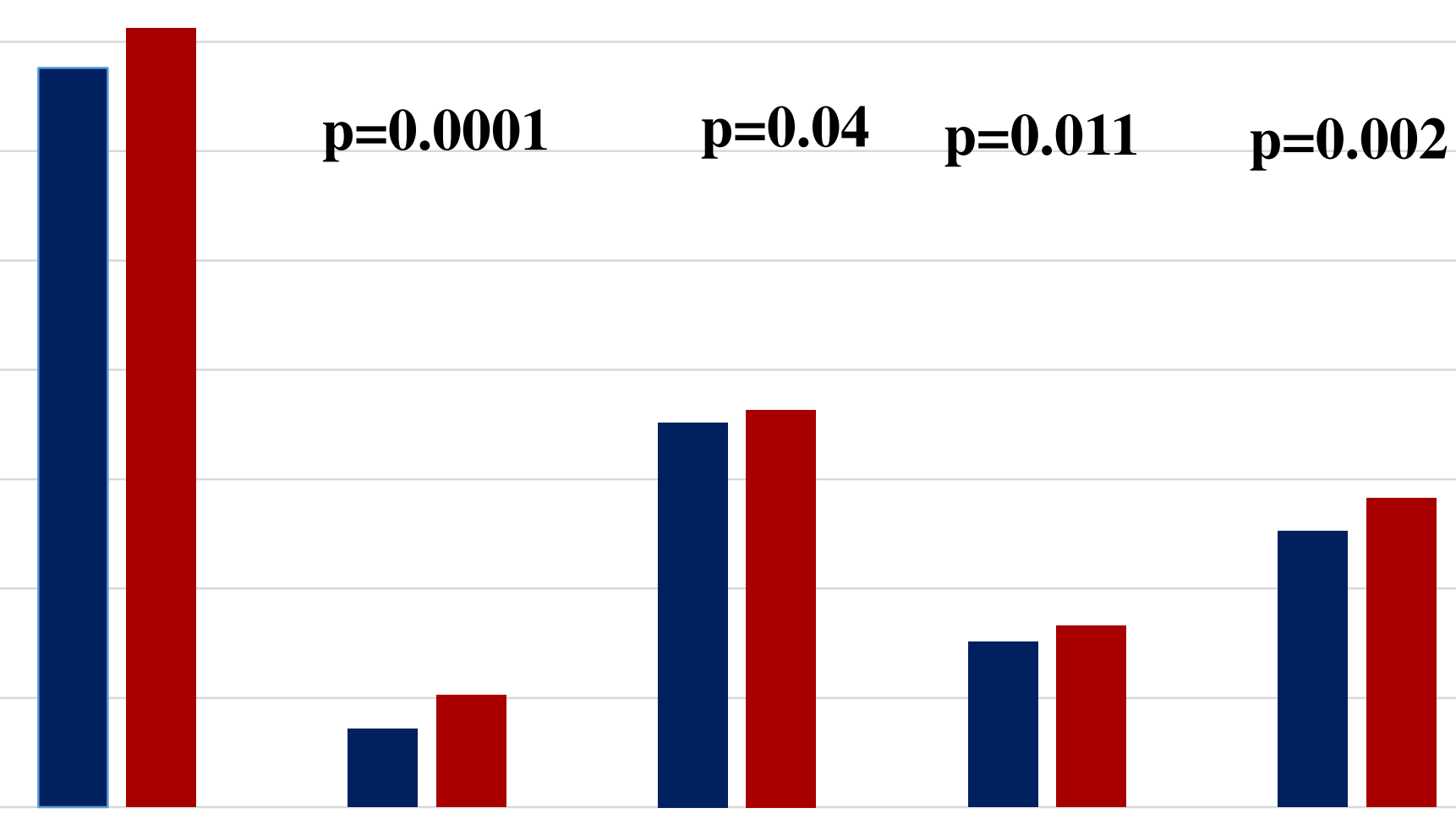

List recognition Story recall $\quad$ Figure recal 